\title{
Green Synthesis of Zinc Oxide Nanoparticles Using Hydro Methanolic Extract of Flueggea leucopyrus Willd Fruit
}

\author{
J Vinnarasi ${ }^{1 *}$, A Anto Arockia Raj ${ }^{2,}$ M Augustin ${ }^{3}$ and G Revathi ${ }^{1}$ \\ ${ }^{1}$ Department of Chemistry, The Standard Fireworks Rajaratnam College for Women \\ (Autonomous), Sivakasi, Tamil Nadu, India \\ ${ }^{2}$ Department of Chemistry, St. Xavier's College (Autonomous), Palayamkottai, Tamil \\ Nadu, India \\ ${ }^{3}$ Department of Physics, St. Xavier's College (Autonomous), Palayamkottai, Tamil \\ Nadu, India \\ *Corresponding Author: J Vinnarasi, Assistant Professor, Department of Chemistry, \\ The Standard Fireworks Rajaratnam College for Women (Autonomous), Sivakasi, \\ Tamil Nadu, India.
}

\begin{abstract}
Biosynthesis of nanoparticle is a vital role in the field of nanotechnology. In the present study zinc oxide nanoparticles synthesis were mediated by green synthesis using hydro methanolic extract of Flueggea leucopyrus Willd fruit. The green synthesized ZnO nanoparticles were analysed by UV-Vis, FT-IR Spectroscopy, X-Ray Diffraction and Scanning Electron Microscopy. The results of the various techniques confirmed the formation of ZnO-NPs. The UV-Vis spectra exhibited the absorption maximum at $360 \mathrm{~nm}$ corresponds to pure ZnO-NP. FT-IR spectra revealed the presence of stretching vibrations of $-\mathrm{O}-\mathrm{H}, \mathrm{C}-\mathrm{H}, \mathrm{C}-\mathrm{N}, \mathrm{C}=\mathrm{O}$ and $\mathrm{Zn}-\mathrm{O}$ involved in the reduction and stabilisation of nanoparticles. The SEM and XRD confirmed the synthesised ZnO-NPs is hexagonal (Wurtzite) shaped and size about $87.59 \mathrm{~nm}$. The antioxidant property was reported using DPPH Radical Scavenging activity. The maximum concentration of ZnO-NPs was shown a promising antioxidant value of $71.22 \pm 1.61$ comparable with the standard vitamin-C. The current study is an attempt to describe an effective, simple and eco-friendly method of ZnO-NPs and to appraise its potential for various therapeutic applications in future.
\end{abstract}

Keywords: F. leucopyrus Fruit; ZnO-NP; XRD; SEM; DPPH Radical

\section{Introduction}

Nanotechnology is one of the emerging fields in $21^{\text {st }}$ century. Nanoparticles are very small sized particles with enhanced catalytic reactivity, thermal conductivity, non-linear optical performance and chemical steadiness owing to its large surface area to volume ratio [1]. Transition metal oxide with nano structure and semiconductors with nano dimensions have attracted considerable interest in numerous areas of science and technology as next generation technologies [2-4]. Nowadays Zinc Oxide nanoparticles are very much essential in various streams of science. Zinc oxide is the most promising inorganic oxides that are extensively used owing to its suitable magnetic, electrical and optical properties [5]. ZnO has been listed as "Generally Recognized as safe" (GRAS) by the US Food and Drug Administration (FDA 21CFR182.8991) [6]. It crystallizes in two main forms, hexagonal Wurtzite and cubic Zinc blende [7]. Traditionally, ZnO nanoparticles are synthesized using physical and chemical processes, which offer higher production rate and produce the better-controlled size of nanoparticles. Nonetheless, these methods are considered unfavourable due to high capital cost, high energy requirements and involve the use of toxic and hazardous chemicals. Consequently, these features result in secondary pollution to the environment. Moreover, a study dem- 
onstrated that the chemical synthesis of nanoparticles is toxic and less biocompatible [8]. Biological fabrication of $\mathrm{ZnO}$ nanoparticles using plants, microorganisms, algae and enzymes are ecologically favourable and sustainable compared to physical and chemical approaches [9]. Flueggea leucopyrus Willd (Family: Euphorbiacea) is one of the medicinally used bushy weed [10]. A bergenin found in hydro methanolic extract of the Flueggea leucopyrus leaves has shown antioxidant and immunomodulatory activities in vitro [11]. The Present study was aimed at green synthesis of Zinc Oxide nanoparticles using hydro-methanolic extract of Flueggea leucopyrus willd Fruit. This use of plant extract has some benefits such as been safe, cost effective, environment friendly, non-hazardous, biocompatible, and large-scale production is plausible [12-15].

\section{Material and Methods}

\section{Collection of plant materials}

Healthy disease-free fruits of Flueggea leucopyrus Willd were collected from foot hills of Western Ghats, Sivanthipuram, Tamil Nadu, India. The voucher specimen (XCH 26879) was deposited in St. Xavier's College Herbarium, Palayamkottai.

\section{Extract preparation}

About $60 \mathrm{~g}$ of air-dried, coarsely powdered F. leucopyrus Willd fruits were extracted by green synthesis using hydro-methanolic cold extraction method. The extraction was carried out about 72 hours. The extracts were concentrated using vacuum evaporator and analysed for further analysis.

\section{Synthesis of zinc oxide nanoparticles}

About $0.22 \mathrm{~g}$ of zinc acetate dihydrate was weighed accurately and dissolved in $100 \mathrm{ml}$ of distilled water. $20 \mathrm{ml}$ of the fruit extract of F. leucopyrus Willd was slowly added to the Zinc acetate dihydrate solution. This mixture was constantly stirred about four hours using magnetic stirrer. The extract was filtered using Whatman filter paper No.1 and centrifuged to remove any undissolved debris. Then the reaction mixture was kept for a day. The change in colour indicates the formation of zinc oxide nanoparticles. The pure Zinc oxide nanoparticles were collected and kept in air tight bottles in a desiccator for further studies [16].

\section{Results and Discussion}

The reaction between the hydro-methanolic extract of Flueggea leucopyrus fruit and zinc acetate dihydrate solution leads to the formation of $\mathrm{ZnO}$ nanoparticle. The bioactive compounds present in the Flueggea leucopyrus fruit can play an important role in the reduction and stabilization of $\mathrm{ZnO}$-NPs. Various analytical methods were used for the characterization of the $\mathrm{ZnO}$-NPs to evaluate their properties like size, shape, morphology and composition.

\section{Visual assessment}

The stage by stage colour change exposes the formation of Zinc oxide Nanoparticles by plant materials. This is one of the significant tests for checking the formation of ZnO-NPs. The colour of the reaction mixture changes from dark brown to pale yellow indicating the synthesis of ZnO-NPs. The pale coloured residue obtained was dried in hot air oven to yield amorphous zinc oxide nano particle.
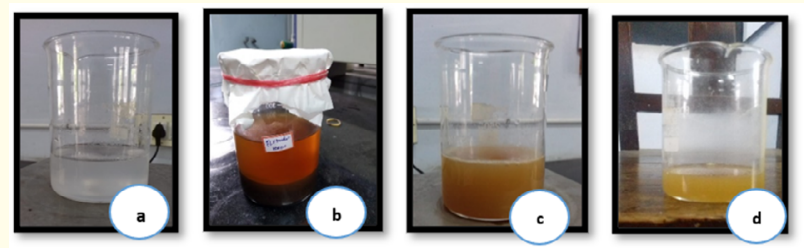

Figure 1: Formation of $\mathrm{ZnO}-\mathrm{NPs}$ using $\mathrm{F}$. leucopyrus fruit.

(a) Zinc acetate dihydrate solution. (b) Methanolic extract of Flueggea leucopyrus fruit. (c) Immediate Colour Change. (d) Formation of Zinc oxide nanoparticles.

\section{UV-visible spectral analysis}

The UV-Visible spectral studies of the green synthesized ZnONPs. were examined using Shimadzu Make UV Spectrophotometer UV-1700 with range of 200-900 $\mathrm{nm}$. The absorption spectrum of the synthesized ZnO NPs using Flueggea leucopyrus fruit extract are shown in figure 2 . The absorption maximum at $360 \mathrm{~nm}$ supports the formation of Zinc oxide nanoparticles. Strong absorption bands of the biosynthesized samples were observed from UV-Visible spectra in the range of 360-363 nm which corresponds to the characteristic band of $\mathrm{ZnO}$ nanoparticles [17]. Absence of any other absorbance peak in the spectra confirms that the synthesized products are pure ZnO-NPs. Furthermore, it is reported that the peak positions of UV-Visible spectra are related with size of nanoparticles and blue shifted as the crystal size of the nanoparticles decreased [18]. 


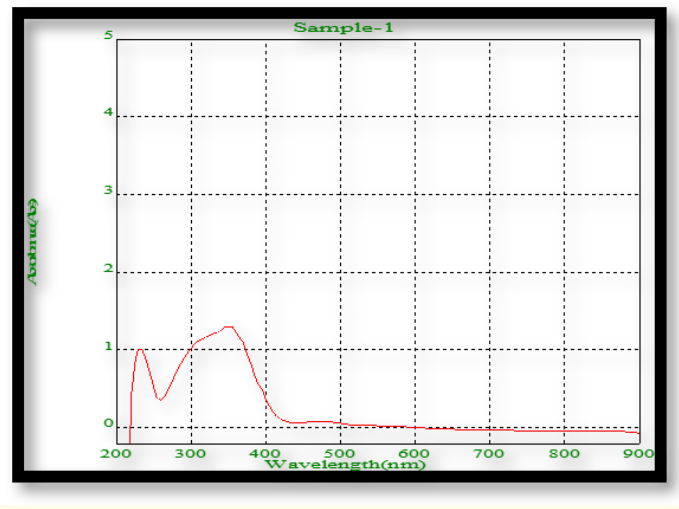

Figure 2: UV-V is spectrum of ZnO-NPs.

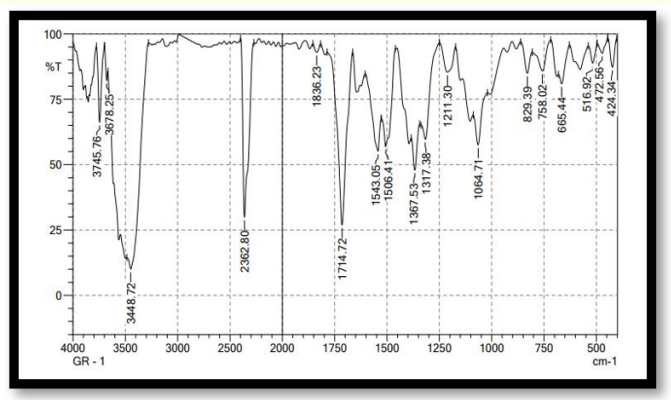

Figure 3: FT-IR spectrum of green synthesized ZnO-NPs.

\section{FT-IR analysis}

The FT-IR spectra of green synthesized ZnO-NPs of Flueggea leucopyrus Fruit were shown in figure 3. The FTIR spectrum of zinc oxide nano particles with absorption peaks situated between 4500 $\mathrm{cm}^{-1}$ and $400 \mathrm{~cm}^{-1}$. A broad Band observed at $3448.12 \mathrm{~cm}^{-1}$ assigned to the stretching of phenolic $\mathrm{O}-\mathrm{H}$ group vibrations. The bands observed at $2362.80 \mathrm{~cm}^{-1}$ could be allocated to-C-C- stretching. A sharp band at $1714.72 \mathrm{~cm}^{-1}$ corresponding to $-\mathrm{C}=0$ group. Two absorption peaks observed at 1543.05 and $1506.41 \mathrm{~cm}^{-1}$ are assigned to the stretching of $\mathrm{C}=\mathrm{C}$ groups. The peaks at $1064.71 \mathrm{~cm}^{-1}$ result from $\mathrm{C}-\mathrm{N}$ stretching of aliphatic amines. The intense absorption peak at $\sim 800$ to $400 \mathrm{~cm}^{-1}$ indicates that the stretching vibrations of $\mathrm{Zn}-\mathrm{O}$ bond. The band formed at $472.56 \mathrm{~cm}^{-1}$ highly supports the presence of Zinc Oxide Nano Particles free from functional groups associated with bioorganic compounds of F. leucopyrus fruit [19].

\section{X-ray diffraction data}

The powder XRD pattern of the prepared $\mathrm{ZnO}$ nanoparticles is recorded with X-Ray Diffractometer (D8 Advance ECO XRCD Systems with SSD160 1 D Detector) (Bruker) at wavelength 1.54060 $\mathrm{A}^{\circ}$. The sample is scanned over $2 \theta$ range $20^{\circ}-90^{\circ}$. Table 1 . Showed the XRD studies of biosynthesized ZnO-NPs using Flueggea leucopyrus fruit. The average size of ZnO-NP is calculated using DebyeScherrer equation.

$\mathrm{D}=\mathrm{K} \lambda / \beta \cos \theta$

Where $D$ is crystalline size, $K$ is shape factor $(0.9), \lambda$ is wavelength of X-ray (1.5406 $\AA$ ), $\beta$ is full width half maxima, $\theta$ is Bragg angle. The mean particle size of the pure $\mathrm{ZnO}-\mathrm{NPs}$ was found around $87.59 \mathrm{~nm}$, which shows some agglomeration of $\mathrm{ZnO}$-NPs.

\begin{tabular}{|l|c|c|c|c|c|}
\hline $\begin{array}{l}\text { No. of } \\
\text { peaks }\end{array}$ & Planes & $\mathbf{2}^{\boldsymbol{\theta}}$ (deg) & $\boldsymbol{\theta}$ (rad) & $\begin{array}{c}\text { FWHM, } \boldsymbol{\beta} \\
\text { (rad) }\end{array}$ & $\begin{array}{c}\text { Size } \\
\text { (nm) }\end{array}$ \\
\hline 1 & 100 & 30.2020 & 0.2636 & 0.1557 & 93.0109 \\
\hline 2 & 002 & 34.2354 & 0.2988 & 0.2279 & 63.5447 \\
\hline 3 & 101 & 42.7018 & 0.3726 & 0.1796 & 80.6344 \\
\hline 4 & 102 & 45.1220 & 0.3938 & 0.1503 & 96.3538 \\
\hline 5 & 110 & 50.8293 & 0.4436 & 0.3441 & 42.0868 \\
\hline 6 & 103 & 60.4054 & 0.5271 & 0.1780 & 81.3609 \\
\hline 7 & 200 & 66.1052 & 0.5769 & 0.1305 & 110.9760 \\
\hline 8 & 201 & 70.6888 & 0.6169 & 0.1176 & 123.1504 \\
\hline 9 & 202 & 77.2106 & 0.6738 & 0.1490 & 97.1989 \\
\hline \multicolumn{5}{|c|}{ Average Size } & 87.5908 \\
\hline
\end{tabular}

Table 1: The ZnO NPs particle size calculation using

Debye- Scherrer's equation and data.

\section{Scanning Electron Microscopy Analysis}

SEM analysis was performed to visualize the shape of nanoparticle. The surface morphology of biosynthesized ZnO-NPs obtained from the Flueggea leucopyrus Fruit were studied by SEM and the results are reported in figure 4 . The particles are having beautiful hexagonal shape as like wurtzite type of structure.

\section{DPPH radical scavenging activity}

In Pharmaceutical science besides nanoscience and technology antioxidant activity plays a key role was carried out by William's method using DPPH assay to evaluate the percentage of scavenging 


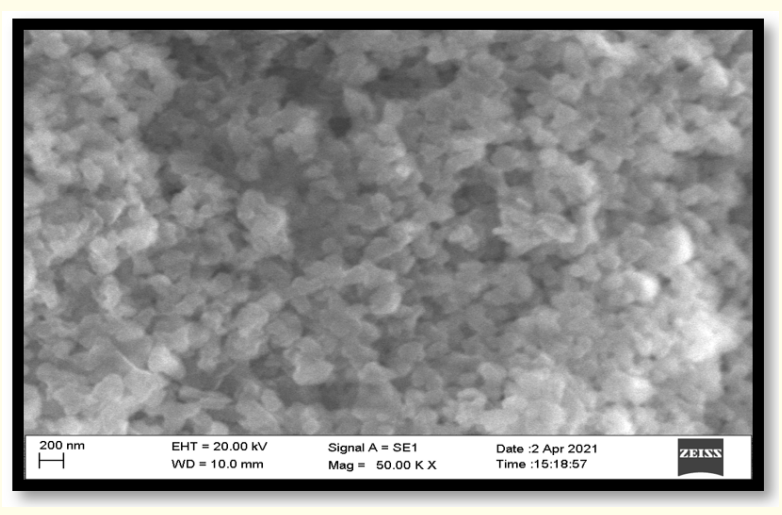

Figure 4: SEM Analysis of ZnO-NPs.

activity [20]. The DPPH radical scavenging activity of green synthesized ZnO-NPs of Flueggea leucopyrus fruit was tabulated in table 2. These measurements revealed that the antioxidant effect increased with increase in the concentration of $\mathrm{ZnO}$ nanoparticles.

Percentage of DPPH Scavenging Inhibition $=A_{o}-A_{t} / A_{o} X 100$

Where

$A_{o}=$ Absorption value of control $(\mathrm{DPPH})$ sample

$A_{t}=$ Absorption value of test sample.

\begin{tabular}{|l|c|c|}
\hline \multirow{2}{*}{ Concentration } & \multicolumn{2}{|c|}{ Percentage of anti-oxidant effect on DPPH } \\
\cline { 2 - 3 } & Vitamin C & ZnO-NPs \\
\hline $10 \mu \mathrm{g}$ & $90.16 \pm 1.76$ & $48.16 \pm 1.56$ \\
\hline $20 \mu \mathrm{g}$ & $92.82 \pm 0.98$ & $52.75 \pm 2.99$ \\
\hline $30 \mu \mathrm{g}$ & $95.44 \pm 1.75$ & $58.82 \pm 1.65$ \\
\hline $40 \mu \mathrm{g}$ & $99.99 \pm 1.65$ & $67.15 \pm 1.97$ \\
\hline $50 \mu \mathrm{g}$ & $99.99 \pm 1.24$ & $71.22 \pm 1.61$ \\
\hline
\end{tabular}

Table 2: Scavenging effect of ZnO-NPs and Vitamin C on DPPH free radical.

All the samples were tested triplicate or constant results. The unstable DPPH solution turns stable by the addition of different dosage of antioxidants ZnO-NPs. This is due to the donation of an electron from Oxygen which is present in the ZnO-NPs to the nitrogen atom of the DPPH molecule. The $50 \mu \mathrm{g}$ of $\mathrm{ZnO}$-NPs shows maximum inhibition value of $71.22 \pm 1.61$ comparable with the standard vitamin-C. From the result we conclude that maximum concentration of ZnO-NPs inhibits the DPPH free radical to yield a stable DPPH molecule.

\section{Conclusion}

In this study, a simple and eco-friendly, biological process have been developed to synthesise ZnO-NPs. It has been characterized using UV-Visible, FT-IR spectral analysis the secondary metabolites present in the hydro-methanolic extracts of $F$. leucopyrus fruit involved in the formation of ZnO-NPs. The biosynthesised ZnO-NPs have hexagonal structures and mean particle size about 87.59 $\mathrm{nm}$ determined from SEM an XRD analysis respectively. The antioxidant behaviour of ZnO-NPs shown this as a potential drug over DPPH radical scavenging activity. This green synthesis of ZnO-NPs using hydro-methanolic extracts of $F$. leucopyrus fruit paved a route for the development of novel drug in the field pharmaceutical and biomedical applications.

\section{Acknowledgments}

The authors are thankful to the management of The Standard Fireworks Rajaratnam College for Women (Autonomous), Sivakasi and St. Xavier's College (Autonomous), Palayamkottai for their continued support.

\section{Bibliography}

1. Happy Agarwal., et al. "A review on green synthesis of zinc oxide nanoparticles - An eco-friendly approach". ResourceEfficient Technologies 3 (2017): 406-413.

2. Zhong Lin Wang. "Materials Properties and Potential Applications in Nanosystems and Biotechnology". Annual Review of Physical Chemistry 55 (2004): 159.

3. Kwon Y J., et al. "Characterization of $\mathrm{ZnO}$ nanopowders synthesized by the polymerized complex method via an organochemical route". Journal of Ceramic Processing Research 3 (2002): 146-149.

4. Aneesh P M., et al. "Synthesis of ZnO nanoparticles by hydrothermal method". Proceedings of SPIE 6639 (2007): 66390J.

5. Goswami M., et al. "Effect of annealing temperatures on the structural and optical properties of zinc oxide nanoparticles prepared by chemical precipitation method". Optik 158 (2018): 1006-1015.

6. FDA (Food and Drug Administration), Washington DC, USA. Select Committee on GRAS Substances (SCOGS) Opinion: Zinc Salts (2015).

7. JL Fierro. "Metal Oxides: Chemistry and Applications". CRC Press (2006): 182. 
8. Raouf Hosseini M and Nasiri Sarvi M. "Recent achievements in the microbial synthesis of semiconductor metal sulfide nanoparticles". Materials Science in Semiconductor Processing 40 (2015): 293-301.

9. Rudeerat Suntako. "Effect of synthesized ZnO nanograins using a precipitation method for the enhanced cushion rubber properties". Materials Letters 158 (2015): 399-402.

10. Anto Arockia Raj A., et al. "Phytochemical and Pharmacognostical analysis of Flueggea leucopyrus Willd". World Journal of Pharmaceutical Research 58 (2016) 1227-1240.

11. Preethi Soysa., et al. "Evaluation of antioxidant and antiproliferative activity of Flueggea leucopyrus Willd (katupila)". BMC Complementary Medicine and Therapies 30 (2014): 274.

12. Abdul H., et al. "Green synthesis and characterization of zinc oxide nanoparticles from Ocimum basilicum L. var. purpurascens Benth.- lamiaceae leaf extract". Materials Letters 131 (2014): 16-18.

13. Folorunso A., et al. "Biosynthesis, characterization and antimicrobial activity of gold nanoparticles from leaf extracts of Annona muricate". Journal of Nanostructure in Chemistry 9 (2019): 111-117.

14. Akintelu S A and Folorunso A S. "Biosynthesis, characterization and antifungal investigation of Ag-Cu nanoparticles from bark extracts of Garcina kola". Stem Cells 10 (2019): 30-37.

15. Akintelu S A and Folorunso A S. "Characterization and antimicrobial investigation of synthesized silver nanoparticles from Annona muricata leaf extracts". Journal of Nanotechnology Nanomedicine and Nanobiotechnology 6 (2019): 1-5.

16. Sharmila Devi R and Gayathri R. "Green Synthesis of Zinc Oxide Nanoparticles by using Hibiscus rosa-sinensis". International Journal of Current Engineering and Technology 4 (2014): 2444-2446.

17. Salahuddin N., et al. "Synthesis and characterization of $\mathrm{ZnO}$ nanoparticles via precipitation method: effect of annealing temperature on particle size". Journal of Nanoscience and Nanotechnology 5 (2015): 82-218.

18. Pranjali P M., et al. "Synthesis and characterization of zinc oxide nano particles by using polyol chemistry for their antimicrobial and antibiofilm activity". Biochemistry and Biophysics Reports 17 (2019): 71-151.
19. Sunday Adewale Akintelu and Aderonke Similoluwa Folorunso. "A Review on Green Synthesis of Zinc Oxide Nanoparticles Using Plant Extracts and Its Biomedical Applications". BioNanoScience 10 (2020): 848-863.

20. Brand-Williams W., et al. "Use of a free radical method to evaluate antioxidant activity". LWT Food Science and Technology 28 (1995): 25-30.

\author{
Volume 5 Issue 12 December 2021 \\ (C) All rights are reserved by J Vinnarasi., et al.
}

